\title{
EFICACIA DE LA CONSTITUCIÓN ANTE LA OMISIÓN LEGISLATIVA
}

\author{
THE EFFECTIVENESS OF THE CONSTITUTION IN FACE OF LEGISLATIVE OMISSION
}

\section{Irina Graciela Cervantes Bravo}

\begin{abstract}
Doctora en Derecho Procesal por la Universidad Complutense de Madrid. Especialista en Derecho Constitucional y Ciencia Política, Docente-Investigadora de la Universidad Autónoma de Nayarit. Miembro del Sistema Nacional de Investigadores nivel 1, Perfil PROMEP y reconocimiento a la trayectoria Académica, miembro del Instituto Iberomericano de Derecho Constitucional y de la Red Internacional de Posgrados en Derecho. Presidenta del Tribunal Estatal Electoral de Nayarit.

Email: irinagraciela@hotmail.com
\end{abstract}

Convidada

RESUMO: La Constitución es una Ley Fundamental que consagra una serie de principios y valores, por ello, es importante que se materialice su contenido, algunos preceptos constitucionales requieren que el legislador desdoble su contenido pero de no existir esa actividad del legislador podría generar la eficacia de la Constitución su aplicación directa aun cuando existe omisión del Parlamento, estas y otras interrogantes abordamos en el presente artículo, a sabiendas que en México el control concreto de constitucionalidad electoral lo asumen los Tribunales Electorales Locales y Federales. Al efecto, los órganos jurisdiccionales federales y locales han emitido sentencias relevantes respecto a la omisión legislativa, mismas que tienen como fin hacer que el legislador en el ámbito de sus competencias realice las adecuaciones o creaciones de las normas necesarias que den funcionalidad a las reformas de la Carta Magna, dándose en el menor tiempo posible. Estos órganos jurisdiccionales tienen la responsabilidad de velar por el cumplimiento de la supremacía constitucional y los instrumentos internacionales, haciendo efectivo los derechos políticos-electorales tutelados. Finalmente, este mecanismo de protección para atender dicha omisión del legislador también contribuye al fortalecimiento de un sistema democrático, la maximización de derechos fundamentales y el respeto a la supremacía constitucional.

Palavras clave: Eficacia. Supremacia constitucional. Omisión.

\begin{abstract}
The Constitution is a Fundamental Law that establishes a series of principles and values, therefore, it is important that its content materialize itself. Some constitutional precepts require that the legislator unfold its content but if there is no such activity, it could generate effectiveness of the Constitution and its direct application even when there is an omission of the Parliament. These and other questions are herein addressed, acnowledging that in Mexico the effective control of the electoral constitutionality is done by the Local and Federal Electoral Courts. To this end, the federal and local jurisdictional bodies have issued relevant judgments regarding the legislative omission, which are intended to créate awareness in the legislator in regard to the scope of its powers to make the necessary legislation adjustments in order to provide functionality to the reforms of Constitution. These jurisdictional bodies have the responsibility to ensure
\end{abstract}


compliance with constitutional supremacy and international instruments, making effective the protected political-electoral rights. Finally, this protection mechanism to address said omission of the legislator also contributes to the strengthening of a democratic system, the maximization of fundamental rights and respect for constitutional supremacy.

Keywords: Efficiency. Constitutional supremacy. Omission

SUMÁRIO: Introducción. 1 El Modelo de Justicia Constitucional en México. 2 Que se entiende por Omision Legislativa. 3 Eficacia Normativa de la Constitución. 4 Sentencias Relevantes sobre Omisión Legislativa Electoral. A manera de conclusion. Fuentes de Consulta.

\section{INTRODUCCIÓN}

Los Tribunales Constitucional tiene un papel protagónico para la consolidación del Estado Constitucional y Democrático de Derecho, desde luego México no es la excepción, en consecuencia se ha fortalecido su modelo de justicia constitucional y convencional, aún falta mucho camino por recorre, para la consolidación del Estado constitucional democratico mexicano, lo aquejan grandes problemas entre ellos; la inseguridad, desigualdad social que existe entre los distinto estratos sociales, el centralismo imperante, altas cifras en corrupción e impunidad.

Ciertamente el fortalecimiento de la democracia mexicana el papel protagónico lo asume el órgano jurisdiccional electoral, encargado no sólo de arbitrar los conflictos electorales sino también de ejercer el control concreto de constitucionalidad y convencionalidad en materia electoral a fin de que las leyes, actos por acción u omision respeten los principios, los derechos fundamentales y en general el contenido de la Ley Suprema, así como de las normas convencionales como un centro en el que todo converger, espacio en el que lo importante no es sólo la ejecución de la Constitución, sino la realización de la misma a través de controles efectivos depositados en manos de la jurisdicción ${ }^{1}$.

La ingería constitucional sigue trabajando en el diseño de su justicia interna, incorporando mecanismo de control que permitan la emancipación de la entidades federativas del monopolio atesorado por la justicia federal, por eso en la última década el legislador local a partir de la experiencia veracruzana en el año 2000 se ha preocupado por estructurar el marco de acción de la justicia constitucional local como pieza clave para el desarrollo del federalismo judiciak, es decir este control de la constitucionalidad no solo se realiza respecto a la Ley Suprema Federal, sino que cada entidad federativa protege su Constitución local.

$\mathrm{Al}$ efecto, la tutela constitucional en materia electoral adquiere singular importancia en razón de que el organo jurisdiccional debe velar porque el legislador no restrinja los derechos gracias a los cuales el proceso político mantiene su calidad democrática pues como sostiene Ely: "los tribunales deben salvaguardar los derechos que permiten a los ciudadanos a participar en el proceso político con voz y con su voto. Si los derechos de libertad de expresión y de sufragio, y otros derechos conexos, no son objeto de la adecuada protección, se menoscaba el correcto funcionamiento del proceso político"2. Aunado a lo anterior, la importancia práctica del control constitucional electoral local lo encontramos en el fortalecimiento del Estado federal, en razón de que la constitucionalidad en entidades federativa atiende a las necesidades propias de su región, misma que son diferentes a lo previsto por la Ley Suprema Federal. Además, los indicadores objetivos de la eficacia practica del control constitucional electoral lo podemos advertir en las sentencias emitidas por las Salas del Tribunal Electoral del Poder Judicial de la federación,

\footnotetext{
${ }^{1}$ ZAGREBELSKY, Gustavo, el derecho dúctil: Ley, Derechos Justicia, $8^{\mathrm{a}}$ edición, Ed. Trotta, Madrid, 2008. p. 14. ${ }^{2}$ ELY Democracy and Distrust citado por FERRERES Víctor, en Control Judicial de la Constitucionalidad de la Ley, Ed. Fontamara México, 2008. 59
}

Revista de Direito Brasileira | Florianópolis, SC | v. 26 | n. 10 | p. 178-194 | Mai./Ago. 2020 
resoluciones que demuestran la existencia de normas electorales inconstitucionales en el ámbito local $^{3}$.

Tanto a nivel federal y local, nos encontramos que existe falta de diseño de la normatividad electoral para protegernos de la inactividad de un legislador que no expide la norma para desarrollar el derecho politico-electoral. Si bien es verdad, que en la práctica los Tribunales Electorales se han pronunciado favorablemente al justiciable para protegerlo ante la omision legislativa, resulta apremiante un diseño normativo acabado de la tutela constitucional electoral ante la omisión legislativa, para eficientar la tutela que protege la supremacía de la constitución, estas y otras reflexiones abordaremos a lo largo del presente artículo.

\section{EL MODELO DE JUSTICIA CONSTITUCIONAL ELECTORAL EN MÉXICO}

La justicia constitucional en México pertenece a un híbrido modelo de justicia constitucional, que se encuentra por así decirlo a caballo entre el control difuso y el concentrado, pues conforme a lo dispuesto en los artículos 103, 105 y 107 de la Carta Magna Federal la Suprema Corte de Justicia de la Nación ostenta la supremacía interpretativa del texto constitucional federal, no obstante, otros órganos del mismo Poder Judicial Federal realizan el control difuso de la constitucionalidad y convencionalidad, Tribunales Colegiados y Unitarios de circuito, los Jueces de Distritos y las Salas del Tribunal Electoral del Poder Judicial Federal. Además con la reforma constitucional del 10 de junio del 2011, se delinea claramente un control difuso que se ejerce en el momento de que cualquier juez al enjuiciar un caso concreto inaplique una Ley ordinaria al considerarla contraria a la Constitución o tratado internacional ${ }^{4}$.

Con tal control de convencionalidad y al convertirse el juez nacional en un interprete de la normativa interamericana aparece como señala Gozaíni un ingrediente no previsto, como lo es "la idea de jurisdicción trasnacional, que aporta reglas y principios comunes para todos los Estados Partes que deben articular sus normas internas con los postulados de los derechos humanos"5. Por tanto ese control difuso puede efectuarse por cualquier juez, no sólo porque la norma electoral que se aplica en el proceso para resolver el conflicto va en contra de la constitución sino porque va en contra de un convenio internacional suscrito y ratificado por México.

Ahora bien, el modelo de justicia constitucional implica la existencia de dos niveles o esferas de gobierno judicial; federal y local, dos órdenes autónomos y no subordinados el uno con el otro, lo cierto es, que el poder judicial federal puede anular decisiones de los jueces ordinarios o tribunales locales y no a la inversa.

\section{A) FEDERAL}

En el ámbito federal la reforma constitucional de $2007^{6}$ dibujó un nuevo escenario para la justicia constitucional electoral en México, con la adición del párrafo sexto del artículo 99 de la Ley Suprema federal se delinea claramente en materia electoral ${ }^{7}$ un sistema de control constitucional compartido entre la Suprema Corte de Justicia de la Nación y el Tribunal Electoral

\footnotetext{
${ }^{3}$ SUP-JRC 494/2007 y su acumulado SUP JRC 496/2007, y SUP-JRC 27/2009 complementar

${ }^{4}$ Vale señalar que el control difuso de convencionalidad no es una cuestión novedosa si tomamos en cuenta que el artículo 133 de la Constitución federal desde antaño establece una supremacía jerárquica de los tratados, constituyendo el bloque de constitucionalidad ${ }^{4}$, no obstante, el legislador mexicano considero necesario reforzar dicho control de la convencionalidad al consagrarlo en el artículo primero constitucional,

${ }^{5}$ GOZAÍNI, Osvaldo Alfredo, problemas actuales del derecho procesal (garantismo vs activismo judicial), Ed. FUNDAP, México, 2002, p.23.

${ }^{6}$ Reforma constitucional publicada en el Diario Oficial de la Federación el 13 de Febrero del 2007 y su correlativo artículo 6 numeral 4 de la Ley General del Sistema de Medios de Impugnación en materia electoral.

${ }^{7}$ En la actualidad con las distintas reformas incorporadas al artículo 99 de la Constitución Federal, el control concreto de constitucionalidad se regula en la fracción X.
}

Revista de Direito Brasileira | Florianópolis, SC | v. 26 | n. 10 | p. 178-194 | Mai./Ago. 2020 
del Poder Judicial de la Federación, tal reforma permitió poner punto final al debate (guerra delle due Corti $)^{8}$ sobre los limites competenciales en el control de la constitucionalidad en materia electoral efectuado por uno u otro órgano9 ${ }^{9}$. Respecto al primer órgano, este sigue ostentando competencia exclusiva en el control abstracto de la constitucionalidad en materia electoral a través de la acción de inconstitucionalidad, instrumento que tiene por objeto denunciar la posible contradicción entre una norma de carácter general electoral, por una parte, y la constitución federal por la otra. Tal acción deberá plantearse dentro de un plazo de 30 días naturales contados a partir del día siguiente de la fecha de publicación de la ley impugnada. Se encuentran legitimados para interponerla la acción de inconstitucionalidad el 33\% de los miembros del parlamento en cada una de las cámaras del Congreso del Unión, de cada una de las legislaturas de los estados o de la asamblea del distrito federal, el Procurador General de la Republica, la Comisión Nacional de los Derechos Humanos, los partidos políticos federales y locales, respecto a estos últimos, su legitimación se limita a impugnar leyes electorales locales. La sentencia recaídas en este juicio cuando es votada por mayoría calificada de ocho ministros, tiene el efecto erga omnes de declara la invalidez de la norma que colisiona con el texto constitucional (Art. 105 fracción II CPEUM) ${ }^{10}$. Es conveniente además añadir que la Ley Suprema limita temporalmente al parlamento en cuanto a la promulgación de leyes electorales pues sólo podrán expedir las mismas, noventas días antes de que inicie el proceso electoral para efectos de su aplicación y durante el desarrollo del proceso electoral respectivo no podrán reformarse o alterarse ningún aspectos fundamental de dicha normativa.

Respecto a la omisión legislativa en el ámbito federal, si bien existe ausencia de normativa que establezca un procedimiento especifico, para tutelar la falta de acción del legislador omiso, sin embargo, recientemente la Suprema Corte de Justicia de la Nación ha dejado claramente determinado que la omisión del legislador puede ser combativa mediante juicio de amparo. Así en la sentencia de amparoen revisión 1359/2015 ordenó: "cuando el acto reclamado sea de carácter negativo o impique una omisión, procede obligar a la autoridad responsable a respetar el derecho de que se trate y a cumplir lo que el mismo exija.... Por lo tanto en este caso concreto esta Primera Sala concede el amparo para el efecto de que el Congreso de la Unión cumpla con la obligación establecida en el artículo transitorio del decreto de reforma constitucional de 10 de febrero de 2014 y, en consecuencia, proceda a emitir una ley que regule el parráfo octavo del artículo 134 de la Constitución"11.

\footnotetext{
${ }^{8}$ Tal como lo cita ASTUDILLO REYES, Cesar, El sistema Mexicano de Justicia Constitucional: Notas para su definición, a 10 años de la reforma constitucional de 1994 enhttp://www.iidpc.org/pdf/doctrinr4Astudillo.pdf p.40. ${ }^{9}$ Controversia generada a raíz de la jurisprudencia en la que el pleno de la Corte monopolizó el control de la constitucionalidad electoral negando contradicción de tesis al Tribunal Electoral Federal por considerar que no eran órganos jurisdiccionales con competencia análoga en cuestiones de constitucionalidad de la norma electoral, al entender que el Tribunal Electoral Federal carecía de dicha competencia en tanto la Corte Suprema tenia competencia exclusiva en el control de constitucionalidad de las leyes electorales conforme a la voluntad del órgano reformador[ contradicción de tesis 2 y 4/2000 P./J 2/2002 y P/J 24/2002] ${ }^{9}$. De igual forma, esta apreciación se fortalece en la jurisprudencia número [P/J 26/2002] al reiterar la Suprema Corte: “ El Tribunal Electoral no está facultado para hacer consideraciones ni pronunciarse sobre la constitucionalidad de una norma general electoral, por ser una atribución exclusiva de este Alto Tribunal, así sea con la única finalidad de determinar su posible inaplicación, o establece la interpretación de un precepto constitucional distinta a la contenida en una jurisprudencia sustentada por la Suprema Corte de Justicia", Tesis jurisprudencia 26/2002 Pleno Suprema Corte de Justicia de la Nación. Semanario Judicial de la Federación, $9^{a}$ época México, 2002.p.83.

${ }^{10}$ Con la reforma constitucional de 1996 se otorgó a la Corte Suprema competencia para conocer de las acciones inconstitucionales contra leyes generales electorales, eliminándose la prohibición expresa que hasta entonces existía en la fracción II del articulo 105 constitucional, para un análisis detallado véase Franco González Salas, José Fernando, "Evolución del Contencioso electoral federal mexicano 1916-1996, Revista Justicia Electoral, Ed. Tribunal Federal Electoral, núm. 8, México, 1996.p. 42.

${ }^{11}$ Véase sentencia de amparo en revisión 1359/2015, recurrente; campaña global por la libertad de expresión A19, Asociación Civil, ministro ponente Arturo Zaldívar, emitida el 15/11/2017, consultable en http://www2.scjn.gob.mx/ConsultaTematica/PaginasPub/DetallePub.aspx?AsuntoID=190443
}

Revista de Direito Brasileira | Florianópolis, SC | v. 26 | n. 10 | p. 178-194 | Mai./Ago. 2020 
Por consiguiente el medio pertinente para combatir la inactividad del legislador pen el ambito federal es el amparo.

Ahora bien, Sala Superior y las cinco salas regionales del Tribunal Electoral del Poder Judicial de la federación, así como los Tribunales Electorales Locales, ejercen el control concreto de la constitucionalidad al momento de enjuiciar las controversias electorales sometidas a su jurisdicción puede desaplicar al caso concreto la norma electoral que trastoque por acción el texto constitucional federal o un tratado internacional. Si bien sobre la omisión legislativa en materia electoral, no se tiene regulación positiva, lo cierto es que la linea jurisprudencial de Sala Superior ha dejado claro que la compentencia contra la omision legislativa corresponde a Sala Superior mediante el Juicio de Revisión Constitucional al indicar:

"La distribución de competencias establecida por el legislador, para las Salas del Tribunal Electoral, con el objeto de conocer de los juicios de revisión constitucional electoral, dejó de prever expresamente a cuál corresponde resolver sobre las impugnaciones en las que se aduzca una omisión legislativa de un Congreso local para legislar en materia político-electoral. En ese sentido, a fin de dar eficacia al sistema integral de medios de impugnación en la materia, y en razón de que la competencia de las Salas Regionales en el juicio de revisión constitucional electoral está acotada por la ley, debe concluirse que la Sala Superior es la competente para conocer de aquellos juicios, cuando ello implique una inobservancia de los principios constitucionales que deben regir toda elección o cuando implique una conculcación a derechos político-electorales de los ciudadanos"12.

Por ultimo, vale señalar que conforme al sistema federal, los Tribunales electorales locales no depende de la estructura orgánica del Tribunal Electoral Federal, sin embargo se encuentran vinculados a la jurisdicción que ejerce este órgano federal, toda vez que el Tribunal Electoral Federal tiene plena jurisdicción para revocar o modificar todo acto o resolución que considere violatorio de legalidad o constitucionalidad electoral, incluso puede dictar un nuevo fallo entrando a dirimir el fondo de la controversia sustituyendo al órgano jurisdiccional local electoral que lo emitió ( artículo 6 numeral tercero Ley General del Sistema de Medios de impugnación).

\section{B) LOCAL}

En el ámbito local el control difuso de la constitucionalidad en materia electoral se deja en manos de un órgano especializado (Tribunal Electoral) que mediante la reforma constitucional del 10 de febrero de 2014 funciona como órgano Autónomo. No obstante, cada entidad federativa en su libertad de configuración legal establece el diseño del control difuso de la constitucionalidad electoral. Este control difuso de la constitucionalidad electoral la realiza el órgano jurisdiccional electoral local a través de medios impugnativos establecido en su legislación electoral, instrumentos que si bien en las distintas entidades federativas presentan matices y cambian su denominación, en general no varía sustancialmente su regulación, contenidos y alcances.

El inacabado diseño normativo de la justicia constitucional electoral en las leyes estatales permite apreciar que la acción de inconstitucionalidad y la omisión legislativa se establecen como procesos constitucionales tendentes a defender la supremacía de la constitución descalificando sus violaciones u omisiones, en consecuencia depurando del ordenamiento jurídico

\footnotetext{
12 Véase jurisprudencia $18 / 2004 \quad$ consultable en
} http://sief.te.gob.mx/iuse/tesisjur.aspx?idtesis=18/2014\&tpoBusqueda=S\&sWord=omisión,legislativa Revista de Direito Brasileira | Florianópolis, SC | v. 26 | n. 10 | p. 178-194 | Mai./Ago. 2020 
leyes electorales que atenta contra su contenido, o bien, completando su regulación cuando es omisa para hacer efectivo tal contenido del derecho politico-electoral.

La acción de inconstitucionalidad y la acción por omisión legislativa en materia electoral, sigue en general los mismos parámetros establecidos para la procedencia de estos mecanismos en cualquier otra materia, sin hacer distinciones, por tanto, nos limitaremos a señalar las particularidades que por propia naturaleza requiere el control constitucional de la omision legislativa.

En principio este instrumentos de control constitucional tiene una legitimación amplia, pues puede interponerse por cualquier ciudadano que tenga interes juridico, no sólo para preservar la supremacía constitucional, sino en base a su "participación democratica, al ejercer el derecho constitucional de los ciudadanos a iniciar leyes, a fin de que puedan participar de manera inmediata en la toma de decisiones públicas gubernamentales, el cual debe ser tutelado por la autoridad electoral. En ese sentido, los ciudadanos tienen interés jurídico para controvertir la omisión de los órganos legislativos de dictaminar los proyectos de creación, modificación, reforma, derogación o abrogación de leyes y decretos que hayan presentado, porque su derecho a iniciar leyes no se agota con la simple presentación de la propuesta, sino que, para su vigencia plena y ejercicio eficaz, es necesario que la autoridad legislativa se pronuncie al respecto; pues asumir una postura contraria, tornaría ineficaz e inútil el ejercicio del aludido derecho político del ciudadano"13.

Conforme a lo anterior, la legitimación para accionar la tutela constitucional que evite y combata la omisión del legislador, la tiene cualquier ciudadano que puede acudir ante los Tribunales Electorales Locales a fin de que lo protejan de ese actuar omiso del parlamento.

Asimismo, la Sala Superior del Tribunal Electoral del Poder Judicial de la Federación, claramente ordenó mediante tesis jurisprudencial 7/2017 que;

"cuando se reclame la omisión legislativa en materia electoral de un congreso estatal, debe cumplirse con el principio de definitividad, mediante el agotamiento del medio de impugnación en el ámbito local, antes de acudir a la Sala Superior, atendiendo al sistema de distribución de competencias entre los órganos jurisdiccionales electorales federales y los correspondientes en las entidades federativas ${ }^{14}$ ".

Ahora bien, un aspecto de singular importancia en el control de constitucionalidad de la norma electoral es el relativo al plazo de la interposición de la tutela constitucional, la importancia de esta cuestión salta a la vista de inmediato toda vez que en materia electoral, los plazos no son una cuestión menor, por el contrario resultan determinantes durante el desarrollo del proceso electoral, por ello la carta magna federal expresamente limita al legislador a no efectuar ninguna modificación trascendente durante el proceso electoral ni dentro de los noventas días en que el mismo vaya a iniciarse. Sin embargo, el plazo para la interposición de la acción de inconstitucionalidad por omisión, el plazo es abierto de forma tal que el ciudadano puede plantear la acción en cualquier momento mientras subsista la omisión (art. 77 Ley de Control Constitucional del Estado de Nayarit), cuestión que si no hay proceso electoral en marcha no tendría mayores implicaciones, no obstante, durante el proceso electoral ordenar al legilslador modificar la normativa electoral para tener vigencia en el propio proceso electoral que se desarrolla, impacta en la prohibición del plazo constitucional previsto en el artículo 105 de la Constitución Federal que establece que "durante el proceso electoral no habrá modificaciones legales fundamentales". Tal tema, requiere un analisis mayor que retomaremos en líneas posteriores.

13 Consultar tesis jurisprudencial identificada bajo el rubro XXIII/2015, http://sief.te.gob.mx/IUSE/tesisjur.aspx?idtesis=XXIII/2015\&tpoBusqueda=S\&sWord=omisión,legislativa $14 \quad$ Véase $\quad$ jurisprudencia $\quad 7 / 2017 \quad$ consultable http://sief.te.gob.mx/IUSE/tesisjur.aspx?idtesis=7/2017\&tpoBusqueda=S\&sWord=omisión,legislativa Revista de Direito Brasileira | Florianópolis, SC | v. 26 | n. 10 | p. 178-194 | Mai./Ago. 2020 


\section{QUE SE ENTIENDE POR OMISION LEGISLATIVA}

La constitución como una norma fundante debe materializar su contenido. En tanto la omision su parte alude a inactividad, inacción y un dejar de hacer algo es una conducta negativa, en el caso que nos ocupa atribuible al legislador que no cumple con su función de legislar cuando así lo ordena el texto constitucional.

La omisión legislativa se configura cuando el legislador no cumple, en un tiempo razonable o determinado por la propia constitución, un mandato concreto de legislar, impuesto expresa o implícitamente por la Constitución.

En consideración de Sagües ${ }^{15}$, cuando no existen previsiones constitucionales expresas para el control de omisiones, las posibles alternativas a ejercer por un Tribunal Constitucional ante dicha circunstancia son:

a) Soluciones con efecto anoticiador: el órgano controlador pone en conocimiento al órgano sobre la existencia de la omisión. "técnica de las recomendaciones al legislador".

b) Soluciones con efecto anoticiador-imperativo: se le hace del conocimiento al órgano y le requieren al omnitente la instrumentación de la medida ausente, otorgándole un plazo al efecto, esto es "orden de actuar".

c) Soluciones con efecto supletorio o de aplicación directa de la Constitución: el órgano legislativo continúa renuente en su accionar, es necesario prever vías para que a través de un efecto supletorio por parte del Tribunal Constitucional, se aplique la ley fundamental.

d) Soluciones con efecto indemnizatorio: el órgano judicial se encuentra impedido de instrumentar integralmente la norma constitucional, corresponde, como última salida en miras del respeto del ordenamiento constitucional, compensar mediante indemnización el perjuicio ocasionado

La omisión implica que el legislador no dicta una ley que debería dictar para hacer real y efectivo el mandato constitucional. La omisión legislativa se genera frente a un no actuar, a pesar de las previsiones constitucionales expresas dirigidas a que las mismas se materialicen en ley, o ante una regulación deficiente.

Fernández Rodríguez considera que para que el silencio del legislador sea contrario a la Constitución es "necesario, primero, que afecte a aquellos deberes, explícitos o no, de legislar que la misma Constitución le pueda imponer (siendo éste el caso más evidente y sencillo de la omisión inconstitucional), ya que basta con que su silencio constituya una indebida forma de cierre de la apertura constitucional propia de las Constituciones democráticas, y en segundo lugar, que su silencio mantenga o cree situaciones jurídicas contrarias a la Constitución"17.

El objeto del proceso en la acción por omisión legislativa en materia electoral se constriñe a evitar un posible el daño por la conducta pasiva del legislador al no legislar sobre contenidos electorales consagrados por la Ley Suprema local en virtud de que el silencio del legislador provoca un indebido cierre de la pirámide constitucional ${ }^{16}$, pues tal como afirma Víctor Bazán: "la Constitución puede ser vulnerada no sólo por acción, sino, también, por omisión, concretamente, en este último caso, cuando no se actúa a pesar de la expresa previsión constitucional dirigida a

\footnotetext{
${ }^{15}$ Néstor Sagues citado en la sentencia http://portal.te.gob.mx/colecciones/sentencias/html/SUP/2013/JRC/SUP-JRC00122-2013.htm

${ }^{16}$ Vid. SAMANIEGO SANTAMARIA, Luis Gerardo, "La Acción por Omisión Legislativa como medio de control constitucional en el Estado de Quintana Roo", en Derecho Constitucional Estatal Memorias del VI y VII Congresos Nacionales de Derechos Constitucionales de los Estados, Ed. UNAM. México, 2009. p. 411 y ss.
} 
que se lo haga o cuando se legisla deficientemente" 17 . Por ello, la legislación de justicia constitucional estatal se pronuncia por evitar la falta de expedición de leyes, decretos, reglamentos, acuerdos, circulares, bando de policía y gobierno, por parte del parlamento, cabildo, consejeros municipales o cualquier autoridad a quien la Constitución o la Ley ordene legislar, no emita tal norma general y dicha omisión provoque vulneración a la Ley Suprema local, su actuar omiso será impugnado.

\section{EFICACIA NORMATIVA DE LA CONSTITUCIÓN}

La Constitución se encuentra en la cúspide del sistema jurídico mexicano. Todo acto o norma debe respetar y apegarse al contenido del cuerpo constitucional, así el artículo 133 de la Constitución federal, establece categóricamente su carácter supremo:

Esta Constitución, las leyes del Congreso de la Unión que emanen de ella y todos los Tratados que estén de acuerdo con la misma, celebrados y que se celebren por el Presidente de la República, con aprobación del Senado, serán la Ley Suprema de toda la Unión. Los jueces de cada Estado se arreglarán a dicha Constitución, leyes y tratados, a pesar de las disposiciones en contrario que pueda haber en las Constituciones o leyes de los Estados ${ }^{18}$.

Conforme a esta base constitucional, los órganos jurisdiccionales están obligados a velar por la prevalencia de las normas constitucionales, así lo ha entendido la Suprema Corte de Justicia de la Nación en su línea jurisprudencial interpretativa del principio de supremacía constitucional relativa al artículo 133 constitucional, determinando:

El numeral superior citado establece expresamente la supremacía constitucional y un orden jerárquico de los ordenamientos legales en el sistema legal nacional, consignando la obligación para los Jueces de los Estados de respetar la Constitución Política de los Estados Unidos Mexicanos, las leyes federales y tratados internacionales, con preferencia a las disposiciones en contrario que pueden señalar las Constituciones y leyes locales (Tesis: P/J 108/2005,5).

La historia nos muestra que la Constitución surge como un freno para limitar las monarquías absolutistas, dado que los actos del gobernante deben ceñirse al texto constitucional, y no de forma arbitraria por el monarca al justificar sus decisiones en un mandato de la divinidad. Pues, tal como señala De Vega, "la Constitución es lex superior, que obliga por igual a gobernantes y gobernados, a través de la cual se pretende controlar y limitar en nombre de la voluntad soberana del pueblo, la voluntad no soberana del gobernante"19 .

La supremacía de la norma fundamental implica garantizar su propia defensa, contando con mecanismos de control para su protección, a fin de que su contenido no pueda ser alterado ni sus preceptos vulnerados o ignorados, como lo establece el artículo 16 de la Declaración de los Derechos del Hombre y el Ciudadano:

Toda sociedad en la cual no esté establecida la garantía de los derechos, ni determinada la separación de los poderes, carece de Constitución ${ }^{20}$

\footnotetext{
${ }^{17}$ Bazán, Víctor, "Respuestas normativas y jurisdiccionales frente a las Omisiones Inconstitucionales, una visión de derecho comparado", en Carbonell, Miguel (coordinador), En busca de las normas ausentes. Ensayos sobre la inconstitucionalidad por omisión, UNAM, México, 2003, p. 99.

Artículo 133, 2017, Constitución Política de los Estados Unidos Mexicanos. 2017. México: Tribunal Electoral del Poder Judicial de la Federación, consultada en línea en http://sitios.te.gob.mx/legislacion/page/seleccion/1).

${ }^{19}$ De Vega, Pedro, La reforma constitucional y la problemática del poder constituyente, Ed, Tecnos, Madrid, 1985.p.15

${ }^{20}$ Jellinek Georg, Trad. Posada Adolfo, La Declaración de los Derechos del Hombre y el Ciudadano, Ed. IIJ-UNAM, México, 2003.p.104
}

Revista de Direito Brasileira | Florianópolis, SC | v. 26 | n. 10 | p. 178-194 | Mai./Ago. 2020 
Ciertamente la Constitución se complementa con normas de origen internacional que interceptan el texto constitucional llegando a formar parte del derecho interno, la Constitución no puede verse como un texto aislado sino como un ordenamiento global, ello se debe en gran medida al auge de la internacionalización de los derechos humanos.

El carácter fundamental de la constitución tal como señala CECILIA MORA DONATO significa que "sus mandatos quedan fuera de la disponibilidad de las fuerzas políticas y que exista una separación de los poderes, es decir, el contenido constitucional no pueden ser alterados o modificados por los poderes públicos en su actuación ordinaria" ${ }^{21}$. Además, un rasgo característico de la ley suprema es que garantice los derechos fundamentales del ciudadano mismos que son oponibles a sus relaciones con el Estado.

Como expone Guastini las constituciones normalmente incluyen:

a) Normas que confieren derechos de libertad a los ciudadanos, regulando de esa forma las relaciones entre los ciudadanos y el poder político.

b) Normas sobre legislación y, más en general, normas que confieren poderes a los órganos del Estado, regulando así la organización del poder político mismo. c) Normas que contienen los valores y principios que informan a todo el ordenamiento jurídico ${ }^{22}$

En la doctrina se consolida cada vez más la idea que la Constitución no sólo encabeza la pirámide normativa, sino que es un bloque que sustenta una serie de principios, valores y los pilares del Estado Constitucional Democrático. "La Constitución no será suprema por su carácter de norma fundante, sino que lo será en la medida que aloja elementos axiológicos que incidan en la vigencia y protección de los derechos humanos, armonizados con los criterios internacionales en dicha materia" 23 .

La norma constitucional en base a su supremacía fundamenta, une y proporciona cohesión a todo el sistema jurídico, y por tanto sus preceptos están investidos de fuerza vinculante directa. Si bien, en la doctrina encontramos posiciones como la de Afonso Da Silva que, consideran que no siempre es posible la aplicación directa de las normas constitucionales, es decir, no siempre es posible que los preceptos constitucionales por si mismos, puedan producir sus consecuencias jurídicas de forma eficaz, puesto que para lograrlo se hace necesario un actividad legislativa posterior, que a partir del precepto constitucional, regule, desdoble o reglamente lo dispuesto en la norma constitucional, para hacerla eficaz, de lo contrario, el mero precepto no podrá surtir todos sus efectos y consecuencias en tanto no se expidan dichas normas reglamentarias.

Concretamente el autor antes citado señala:

Nuestra Constitución, como la mayoría de las cartas políticas contemporáneas contiene reglas de diversos tipos, función y naturaleza, por postular finalidades diferentes, más coordenadas e interrelacionadas entre sí, formando un sistema de normas que se condicionan recíprocamente. Algunas de ellas son plenamente eficaces y de aplicabilidad inmediata; otras son de eficacia reducida, dependen de una legislación que las integre en sentido y actúen en su incidencia, no son de aplicabilidad inmediata sino son aplicables hasta donde se puedan.

A sabiendas que la Constitución no puede regularlo todo directamente, ni es oportuno que lo haga, se confiere entonces al poder legislativo común, la tarea de desarrollar un principio fundamental ya sancionado en la propia norma,

\footnotetext{
${ }^{21}$ Mora Donato, Cecilia, El valor de la Constitución Normativa, Ed. IIJ-UNAM, México. p. 9.

${ }^{22}$ Guastini, Ricardo, Estudios de Teoría Constitucional, Ed. Fontamara, México, 2007. pp. 29-30

${ }^{23}$ Del Rosario Rodríguez, Marcos Francisco. Junio 2011. La supremacía constitucional: naturaleza y alcances, vol. 20, núm. 1, Colombia: Díkaion: p.106
}

Revista de Direito Brasileira | Florianópolis, SC | v. 26 | n. 10 | p. 178-194 | Mai./Ago. 2020 
manteniendo su supremacía, en tales casos, el propio constituyente en su soberanía, limita su propio poder, atribuyendo a los órganos legislativos la incumbencia de dar origen a normas que confieren cuerpo y sustancia a los principios directivos. ${ }^{24}$.

A este problema la doctrina le ha denominado la eficacia de las normas constitucionales. En tal sentido, eficacia alude a la capacidad de una norma para producir efectos jurídicos, dichos efectos pueden generarse de forma directa o bien de manera indirecta. Ciertamente, las normas constitucionales pueden clasificarse como normas de eficacia directa y normas de eficacia indirecta; las primeras se definen como aquellas normas constitucionales cuya estructura es completa, de forma tal que pueden servir de regla en casos concretos, por tanto es posible que los gobernados fundamenten sus reclamos o demandas en ellos. Esto quiere decir, que pueden ser aplicadas de forma directa por los destinatarios y operadores del sistema jurídico, ya que despliegan desde el primer momento toda su eficacia jurídica, en consecuencia tienen una fuerza normativa plena e inmediata.

Por su parte, las normas de eficacia indirecta, en este rubro se engloban las normas constitucionales, que contrario a las anteriores, no son lo suficientemente completas para aplicarse de forma directa a casos concretos, de manera que aunque son válidas, para ser aplicadas y desplegar la totalidad de sus efectos, requieren de la interpositio legislatoris, es decir un desarrollo o instrumentación posterior por parte de legislador para tornarlas plenamente operativas y eficaces.

Dentro de las normas de eficacia indirecta como en una especie de sub clasificación, se pueden encontrarse una subcategoría a la que denomina normas constitucionales de eficacia diferida, se trata de las normas de organización, que necesitan una disciplina normativa posterior a la establecida por la Constitución; es decir requieren de una ley ordinaria que establezca con detalle la forma e instrumentación de lo que ellas primariamente determinan ${ }^{25}$.

Evidentemente las normas que adicionó la reforma constitucional política-electoral de 10 de febrero de $2014^{26}$, al incorporarse al texto constitucional impregna de la supremacía

\footnotetext{
${ }^{24}$ Da Silva 2003,79 Da Silva, José Alfonso. 2003 Aplicabilidad de las normas constitucionales. [en línea]. Trad. González Martín Nuria. México: IIJ-UNAM. Colección Disponible en web: http://biblio.juridicas.unam.mx/libros/3/1000/6.pdf (consultada 25 de noviembre 2015)

${ }^{25}$ Zagrebelsky, Gustavo. 2008. Principios y votos. El Tribunal Constitucional y la política, trad. de Manuel Martínez Neira, Madrid: Ed. Trotta, pp. 79-81.
}

- $\quad{ }^{26}$ Entre otros temas que modifica la reforma política electoral de 10 de febrero de 2014 , encontramos: Nombramiento de las autoridades electorales locales depende del INE(consejeros), Magistrados Electorales locales se nombrarán por el Senado de la Republica.

- Posibilidad del ejecutivo de formar un gobierno de coalición con otras fuerzas políticas. Asemejándose a lo que el doctor Diego Valadés llama gobierno de gabinete en razón de que existirá un control parlamentario del gabinete del ejecutivo a través del senado respecto al nombramiento de algunos Secretario de Estados.

- $\quad$ Se permite la reelección inmediata de legisladores locales y federales, así como los miembros del ayuntamiento.

- $\quad$ Se aumenta el umbral al tres por ciento de la votación válida emitida para mantener el registro como partido político nacional o estatal.

- Se establece que en caso de nulidad de la elección, se convocará a una elección extraordinaria, sin que pueda participar persona sancionada.

- Se encarga al Congreso de la Unión expedir a más tardar el 30 de abril de 2014 las leyes generales que regulen a los partidos políticos nacionales, los procedimientos y delitos electorales, así como las normas que establezcan las sanciones aplicables a denuncias sin sentido.

- Los consejeros del Instituto Nacional Electoral (INE) serán seleccionados por una comisión integrada por representantes de la Cámara de Diputados, la Comisión Nacional de Derechos Humanos (CNDH) y el Instituto Federal de Acceso a la Información Pública (IFAI);

Revista de Direito Brasileira | Florianópolis, SC | v. 26 | n. 10 | p. 178-194 | Mai./Ago. 2020 
constitucional, por consiguiente se le reconoce eficacia plena y directa, respecto a los fines para los cuales fue modificada la Constitución, como por ejemplo para incorporar límite constitucional a la sobre representación de los partidos en los parlamentos locales de México, no es una cuestión fácil determinar la justiciabilidad y aplicación directa de la norma constitucional que establece el límite máximo a la representación de los partidos políticos en la legislatura local, para hacerlo es necesario distinguir a qué tipo de derechos se refiere la citada reforma constitucional, pues tal como lo expone Ruipérez:

"Desde los parámetros de un constitucionalismo democrático y social que se inaugura con el Texto de Weimar, y que se consolida con las Constituciones aprobadas desde 1945, la concepción iusnaturalista de la libertad civil, que hace que los derechos fundamentales se entiendan como algo anterior y, en todo caso, ajeno al Estado mismo, que determinaba que los mismos tan sólo son eficaces, es decir, oponibles a la actuación de los poderes públicos en la medida en que éstos los desarrollaban legislativamente", con el tiempo esto ha variado para pasar a ser comprendidos como un contenido de la voluntad soberana del Poder Constituyente y por ello son de obligado cumplimiento tanto por los poderes públicos como por los privados"27

Así por ejemplo la mera constitucionalización de un derecho como el de huelga bastaría para que el ciudadano pudiera alegarlo ante los tribunales aun cuando no se encuentre reglamentado y que, al no poder ya ignorar el juez la disposición constitucional, el ciudadano no puede ser condenado si se va a huelga ${ }^{28}$. Cosa distinta, sucede con otros derechos constitucionales pues se trata de derechos que implican una actividad posterior del legislador ordinario para su correcto y adecuado ejercicio, como este tipo de derecho encontramos según indica Ruipérez:

"el derecho a ser elegido como concejal que corresponde a todos los ciudadanos europeos que tengan residencia administrativa, que fue impuesto por el tratado de Maastricht. No cabe duda, de que una vez que se reformó el artículo 13 y entró en vigor la reforma, éste era un derecho del que eran titulares todos los ciudadanos europeos. Ahora bien, para que el mismo pudiera ser ejercido de

- Se fortalece el sistema de fiscalización de los topes en gastos de campaña y se establece sanción para denuncias frivola.

- Se limita la sobre y sub representación en la distribución de curules del congreso local, con topes mínimos y máximos de representación proporcional de tal forma que ningún partido sobrepase el $60 \%$ de la integración de la cámara local.

- Se prevé que la ley establezca un sistema de nulidades de las elecciones federales o locales por violaciones graves, dolosas y determinantes, cuando se exceda el gasto de campaña en un cinco por ciento del monto total autorizado.

- Se deberá garantizar equidad en la contienda a los candidatos independiente, mediante el acceso a los medios de comunicación

- Se ordena a los partidos políticos garantizar mediante la paridad de género las candidaturas de legisladores federales locales.

\footnotetext{
${ }^{27}$ Ruipérez Alamillo, Javier, Reforma versus Revolución, Ed. Porrúa, México, 2014.p 33.

${ }^{28}$ El citado autor indica que en el derecho español el Derecho de huelga es el único que todavía no ha sido desarrollado por una Ley Orgánica. Sin embargo, el mismo, y así lo estableció el Tribunal Constitucional, es ejercible libremente por los ciudadanos sin más requisito que el de que han de cumplir las condiciones que la propia Constitución española establece, los laboralistas dicen que del mero tenor del artículo 28 se desprende que lo único que está prohibido en España es el ejercicio de lo que ellos llaman "huelga salvaje", es decir que no haya sido convocada por los sindicatos. Lo que, importa decirlo, tanto más cuanto es uno de los grandes aciertos del Tribunal Constitucional de España, no excluye la obligación de los poderes constituidos de proceder a la regulación legal de este derecho (lo que se deriva de la ya aludida lógica de la doctrina de la concesio imperii como fundamento último de todo el edificio constitucional.
}

Revista de Direito Brasileira | Florianópolis, SC | v. 26 | n. 10 | p. 178-194 | Mai./Ago. 2020 
una manera real era necesario que se normase para hacerlo posible, así como el que se adecuase el censo. Lo que, a la postre, determinó que no pudieron ser votados en las primeras elecciones municipales que se efectuaron tras la reforma de 1992, tampoco pudieron hacerlo en las segundas, hasta en tanto se diseñó la normativa electoral respectiva". O bien otro ejemplo sería el derecho de objeción de conciencia para no prestar el servicio militar, derecho que no fue ejercible en España, hasta que se estableció la regulación de este derecho y el mecanismo procesal para su interposición. ${ }^{29}$

Conforme a este tipo de derechos constitucionales, expuestos por el anterior autor, estamos en posibilidad de afirmar que la reforma constitucional electoral que entre otras cosas que estableció el límite a la sobre representación de los partidos políticos en el Congreso local, es un tipo de derechos de eficacia constitucional plena, puede alegarse su reconocimiento ante el órgano jurisdiccional electoral, sin necesidad de que el legislador local articule un procedimiento específico para poder hacer efectivo el límite a la representación al ser directamente aplicable.

El límite constitucional a la representación de los partidos en el Congreso local, es una norma de eficacia plena y directa, no diferida, pues contiene una base constitucional que puede ser aplicada directamente por el órgano jurisdiccional electoral quien se encuentra obligado a velar por la prevalencia de la supremacía constitucional, como se trata de una base constitucional general, que debe ser observada por las entidades federativas, no se requiere de un trabajo posterior del legislador local, que la dote de contenido en la legislación secundaria para poder hacerla efectiva, si bien el legislador local está obligado a reproducir este límite en la legislación electoral local, lo cierto es que no se requiere un diseño de normativa para hacerlo efectivo y aplicarlo directamente, pues es un mandato constitucional que deb cumplirse aun cuando la legislación secundaria sea omisa, aplicándose directamente el limite a la representación dispuesto por el texto constitucional, pues conforme lo ordenado por la fracción II del artículo 116 constitucional, las entidades federativas están obligadas al integrar su Congreso local por diputados electos por los principios de mayoría relativa y de representación proporcional ${ }^{30}$, debiendo observar que ningún partido por si sólo rebase en su representación, un porcentaje del total de la integración de la legislatura, superior en ocho puntos a su porcentaje de votación emitida, este límite que introduce la reforma constitucional electoral, si es posible aplicarlo directamente por el órgano jurisdiccional electoral, sin embargo, lo ideal es que ordene al legislador que cumplan con su función y subsane la omisión legislativa existente.

Conforme al pacto federal las entidades federativas en pleno uso de su soberanía y autonomía reciben el mandato constitucional al ámbito local, algunas de estas normas requieren de un trabajo posterior del legislador local, en el que se instrumente las modalidades y condiciones para su ejercicio, concretándolas a través de una actividad normativa posterior que permite desdoblar su contenido, al requerirse el trabajo del legislador que dote de contenido a la reforma constitucional se convierten en normas constitucionales de eficacia diferida, esto es verdad sólo respecto a normas constitucionales como las que se dejan en manos del legislador el diseñó de una fórmula electoral para la distribución de los votos en escaño, pues las normas que entrañan la fórmula electoral, es una norma constitucional de eficacia diferida, pues por mandato constitucional la competencia exclusiva para el diseño de la fórmula en la integración del Congreso estatal recae en el legislador local, dado que el mismo texto constitucional mandata que el diseño del modelo para la integración de los miembros del parlamento local por ambos principios; mayoría y representación proporcional, se realizara conforme lo determinen las leyes locales, lo que implica un trabajo del legislador local que reglamente la base constitucional, sin que ello atente contra la

\footnotetext{
${ }^{29}$ Ibídem

${ }^{30}$ El número de diputados que diseñen para cada principio, depende de cada entidad federativa, al tener soberanía y competencia exclusiva en cuanto al diseño de su sistema electoral.
} 
supremacía constitucional ni mucho menos con la eficacia de la normas constitucionales, o en el caso de otras disposiciones que introduce la citada reforma constitucional que conlleva el significado de ser regla sustancial de derecho, como lo es el entramado normativo para el nombramiento de las autoridades judiciales electorales locales, pues tal como aconteció con la facultad del Senado de la República para el nombramiento de las autoridades jurisdiccionales electorales locales, pospuso el nombramiento de los magistrados electorales locales, en tanto los legisladores locales, como es el caso de Nayarit, desdoblara y actualizaran su normativa recepcionando estas normas de la reforma constitucional ${ }^{31}$, porque este tipo de normas constitucionales son normas de eficacia diferida y programáticas, sin controlar la omisión del legislador inactivo.

Cosa muy distinta sucede con la norma constitucional que introduce el límite a la representación por ambos principios, pues tal como lo establece el propio texto del citado artículo 116 fracción II, es una base constitucional que tiene una eficacia plena, caracterizándose por su posibilidad de aplicación directa, porque está dotadas de todos los medios y elementos necesarios para su ejecutoriedad ${ }^{32}$. En este último supuesto, es en el que se ubica la norma constitucional del límite que evitan la representación excesiva de los partidos políticos en el Parlamento, porque puede ser ejecutada dicha norma constitucional aun cuando no se incorpore dicho límite en la legislación local.

Pues, como bien sostiene el mismo autor Da Silva, la normas sobre el sistema proporcional son normas constitucionales de eficacia plena y aplicación directa, así lo establece el autor en comento al referirse a la Constitución brasileña, indicando ejemplos de normas constitucionales de eficacia plena con posibilidad de materializarse aun cuando no exista su desdoblamiento por la legislación ordinaria, tales como; la que establece que la "Cámara de Diputados se compone de representantes del pueblo, electos, por el sistema proporcional en cada Estado, en cada territorio y en el Distrito Federal"; o aquellas otras normas constitucionales que establecen que "el Poder Legislativo es ejercido por el Congreso Nacional y se compone de la Cámara de Diputados y del Senado Federal", o la norma constitucional que establece, "cada legislatura durará cuatro años"( Da Silva 2003,85), en este tipo de normas constitucionales de eficacia plena en el que se encuentra el límite a la sobre representación de los partidos políticos, no es necesario como indica la sentencia que glosamos modificar las regla prevista en la legislación electoral de Nayarit, para poder aplicar el límite en la asignación de diputados por el principio de representación proporcional, porque una vez que se siga la fórmula electoral para la asignación de diputados de representación proporcional previsto en la legislación respectiva, por la autoridad electoral local puede aplicarse puede aplicarse directamente los dispuesto en el límite constitucional a la representación de los partidos políticos. Como bien dice Da Silva, las normas de eficacia constitucional plena "no tratan de regular una materia en sí, lo que hacen es definir ciertas situaciones, comportamientos o intereses vinculados a determinada materia. Así cuando la norma constitucional establece con precisión, cuál es la conducta positiva o negativa a seguir, relativa al interés descrito en la norma, es posible concluir que esta norma constitucional es completa y se encuentra dotada de plena eficacia jurídica y no necesitan de otra normas para su ejecutoriedad"33

\footnotetext{
${ }^{31}$ Véase dictamen de la Comisión de Justicia del Senado de la República, por el que se pronuncia sobre la elegibilidad de los candidatos para ocupar el cargo de Magistrados de los Órganos Jurisdiccionales Locales en Materia Electoral de los Estados de Chihuahua, Coahuila, Quintana Roo y Nayarit, de fecha 03 de diciembre, 2015. Dictamen Consultado en línea, 10/04/2017, disponible en http://www.senado.gob.mx/comisiones/justicia/docs/Dictamen_MOJL.pdf.

${ }^{32}$ Da Silva 2003,86

${ }^{33}$ Da Silva 2003,77
}

Revista de Direito Brasileira | Florianópolis, SC | v. 26 | n. 10 | p. 178-194 | Mai./Ago. 2020 


\section{SENTENCIAS RELEVANTES SOBRE OMISIÓN LEGISLATIVA ELECTORAL}

Una sentencia que venimos comentando con antelación, es la resolución emitida por la Sala Superior del Tribunal Electoral del Poder Judicial Federal en el Juicio de Revisión Constitucional SUP-REC-892/2014 ${ }^{34}$, ordenó modificar al sistema de representación proporcional de los partidos ante el Congreso local, en el proceso electoral del Estado de Nayarit, en virtud de los topes mínimos y máximos de representación de los partidos en el parlamento local se modificaron con la reforma constitucional del 10 de febrero de 2014, sin que existiera el desdoblamiento de la reforma política electoral en la legislación de la citada entidad federativa. Entre otras cosas en el nucleo toral de la sentencia se argumenta que al tratarse de una reforma constitucional federal, con independencia de que se estuviera desarrollando el proceso electoral local, se debería aplicar directamente la Constitución federal, al existir una omisión legislativa, cambiando con ello, las reglas de asignación de escaños a los diferentes partidos que participaron en el proceso, en tal contexto podemos decir que el órgano jurisdiccional electoral federal, asumiendo en plenitud un papel de legislador negativo, aplica directamente las disposiciones constitucionales sobre el sistema de representación proporcional diseñando por la reforma constitucional, cuando el proceso se desarrollaba, saltándose el límite temporal de no modificar normas electorales noventas días antes de que inicie un proceso electoral que establece el penúltimo párrafo de la fracción segunda del artículo 105 de la Constitución federal, para que pueda promulgarse y publicarse las normas electorales que regirá al proceso electoral respectivo, durante el desarrollo de dicho proceso no podrá realizarse modificaciones legales fundamentales, con tal decisión jurisdiccional se pone de manifiesto que a fin de brindar una mayor protección de los derechos electorales de los partidos minoritarios y propiciar la pluralidad en el parlamento local, el órgano jurisdiccional federal revoca la sentencia de los jueces electorales locales y Sala regional Guadalajara.

Con tales modificaciones al sistema de representación proporcional en el ámbito local, queda claro que el órgano revisor de la Constitución apuesta al pluralismo político tal como establecen las directrices internacionales, a fin de que las decisiones que se tomen en los parlamento locales se consense entre las fuerzas políticas que lo integran, sin que un partido pueda asumir decisiones de forma mayoritaria, pues este sistema busca la armónica coexistencia de pluralidad, representatividad y proporcionalidad, al establecerse reglas, como son una barrera legal para tener derecho a participar en la asignación de curules por el principio de representación proporcional, así como límites en cuanto al número de diputados que un partido político puede tener por ambos principios, y límites a la sobre y sub representación de un partido político. Con estas nuevas reglas de la representación proporcional se deduce que el parlamento local, como órgano plural, podrá ejercer un mayor control de las políticas públicas que impulse el ejecutivo local, pues este último, tendrá que propiciar el dialogo con el parlamento para que sus políticas de gobierno lleguen a buen puerto.

Por otra parte, en la sentencia SUP-JRC-122/20013 emitida por Sala Superior del Tribunal Electoral Federal al tutelar contra la omisión legislativa, entiende que la omisión legislativa absoluta por parte del Congreso del Estado de Tamaulipas de no expedir la normativa para hacer efectiva las candidaturas independientes y las consultas públicas, vulnera el texto constitucional que ordeno realizarlo, por tanto, ordena la emisión de las normas secundarias con el fin de dar regularidad al mandato constitucional. En la sentencia en comento se concluye que la trasgresión a la Constitución surge, en general, desde el momento en que el órgano legislativo incumple el ejercicio de una facultad de ejercicio obligatorio, pues las omisiones legislativas absolutas pueden violentar los derechos humanos, así como los principios constitucionales que rigen las elecciones.

\footnotetext{
${ }^{34}$ Véase SUP-REC 892/2014,en http://portal.te.gob.mx/colecciones/sentencias/html/SUP/2014/REC/SUP-REC-
} 00892-2014.htm

Revista de Direito Brasileira | Florianópolis, SC | v. 26 | n. 10 | p. 178-194 | Mai./Ago. 2020 
Pues, si algún Congreso local reciba un mandato vinculado a una facultad de esa naturaleza, sin pronunciarse al respecto, vulnera la Constitución, dado que dicha conducta merma la plena eficacia de la Ley Fundamental.

Después de todo, la trasgresión a la Constitución surge, en general, desde el momento en que el órgano legislativo incumple el ejercicio de una facultad de ejercicio obligatorio. Al existir la omisión legislativa es necesaria intervención del órgano jurisdiccional electoral encargado de garantizar que todos los actos y resoluciones se sujeten a los principios de constitucionalidad y legalidad, pues de lo contrario se dejaría en manos del legislador secundario la determinación del ejercicio de un derecho fundamental.

En base a lo anterior, se declara actualizada la omisión legislativa atribuida al Congreso de Tamaulipas, pues tal abstención de legislar se da en contra de una exigencia constitucional de hacer, por lo que al existir un mandato constitucional concreto que obliga al legislador local a adoptar medidas legislativas de materialización constitucional en la materia político-electoral, por lo que finalmente en la sentencia en comento se ordena emitir la legislación atinente, a fin de privilegiar los derechos humanos de los ciudadanos del Estado de Tamaulipas, estimando que las adecuaciones o creaciones de las normas necesarias que den funcionalidad a la reforma y adición de la Carta Magna, deben darse en el menor tiempo posible ${ }^{35}$.

Ahora bien, en la sentencia SUP-JDC-210/2017, el órgano jurisdiccional electoral determina que no se materializaba ningún tipo de omisión legislativa, pues en su consideración el reconocimiento y regulación del derecho a votar desde el extranjero en elecciones locales constituye una competencia de ejercicio potestativo para el Congreso de cada entidad federativa y, por tanto, la falta de reconocimiento y regulación de ese ámbito no actualiza, por sí misma, una omisión legislativa que transgreda el derecho activo al sufragio. Ello, toda vez que los congresos cuentan con la potestad para crear normas generales y decidir las circunstancias en las que regularán dicha prerrogativa; debiendo ponderar, por un lado, el derecho al voto de la ciudadanía y, por otro, garantizar que éste se ejerza en elecciones libres, auténticas y periódicas, atendiendo a las circunstancias particulares de cada entidad federativa. Lo anterior considerando que no existe una obligación constitucional o convencional a cargo del Estado mexicano de reconocer el derecho al voto desde el extranjero en todas y cada una las elecciones que se lleven a cabo en el territorio nacional, siendo que ese derecho no es absoluto y, por tanto, puede estar sujeto válidamente a condiciones y limitaciones por razón de residencia.

Consideramos que la principal condición para no estimar procedente la omisión legislativa en la sentencia en comento, es que la Constitución no ordena expresamente garantizar el voto en el extranjero, sino que tal posibilidad se regula en la legislación secundaria ${ }^{36}$.

\section{A MANERA DE CONCLUSIÓN}

En la actualidad, el órgano jurisdiccional electoral no se limita a resolver la controversia sometida a su conocimiento actuando a legalidad, es decir aplicando sólo la Ley electoral al caso concreto, sino que tiene la responsabilidad de velar por el cumplimiento de la supremacía constitucional y los instrumentos internacionales logrando armonizar la normativa electoral interna con las normas constitucionales y tratados internacionales.

Por ello, es pertinente un diseño acabado de la normativa que regule la omision legislativa electoral, para hacer efectivo los derechos politicos- electorales tutelados por la Constitución, dado que si bien en la práctica nos encontramos con decisiones jurisdiccionales que ante falta de

\footnotetext{
${ }^{35} \mathrm{http} / / /$ portal.te.gob.mx/colecciones/sentencias/html/SUP/2013/JRC/SUP-JRC-00122-2013.htm

${ }^{36}$ Véase sentencia

210/2017http://sief.te.gob.mx/iuse/tesisjur.aspx?idtesis=III/2018\&tpoBusqueda=A\&sWord=
} 
actividad del legislador no sólo ordenan subsanar la omisión, sino que aplican directamente la Constitución aun cuando persiste la falta de legislación, para efecto de garantizar la eficacia plena de la Constitución.

Finalmente la protección jurisdiccional ante la omisión de un legislador inactivo, contribuye al fortalecimiento de un sistema democrático, al fortalecimiento del Estado convencional y constitucional de derecho, y a la maximización de los derechos fundamentales entre ellos, los derechos políticos electorales.

\section{FUENTES DE CONSULTA}

ASTUDILLO REYES, Cesar, El sistema Mexicano de Justicia Constitucional: Notas para su definición, a 10 años de la reforma constitucional de 1994 en

http://www.iidpc.org/pdf/doctrinr4Astudillo.pdf p.40

Bazán, Víctor, "Respuestas normativas y jurisdiccionales frente a las Omisiones Inconstitucionales , una visión de derecho comparado", en Carbonell, Miguel (coordinador), En busca de las normas ausentes. Ensayos sobre la inconstitucionalidad por omisión, UNAM, México, 2003.

Da Silva, José Alfonso, Aplicabilidad de las normas constitucionales. [en línea]. Trad. González Martín Nuria, Ed. IIJ-UNAM, México, 2003, Colección Disponible en web: http://biblio.juridicas.unam.mx/libros/3/1000/6.pdf (consultada 25 de febrero 2018)

De Vega, Pedro, La reforma constitucional y la problemática del poder constituyente, Ed, Tecnos, Madrid, 1985.p.15

Del Rosario Rodríguez, Marcos Francisco, La supremacía constitucional: naturaleza y alcances, vol. 20, núm. 1, Ed. Díkaion, Colombia: Junio 2011. pp. 97-117.

ELY Democracy and Distrust citado por FERRERES Víctor, en Control Judicial de la Constitucionalidad de la Ley, Ed. Fontamara México, 2008. 59

Ferrajoli, Luigi, "Hacia una teoría jurídica de la democracia", Teoría de la democracia, dos perspectivas comparadas, trad. de Lorenzo Córdova, Ed. IFE, México, 2002.

GOZAÍNI, Osvaldo Alfredo, problemas actuales del derecho procesal (garantismo vs activismo judicial), Ed. FUNDAP, México, 2002, p.23.

Guastini, Ricardo, Estudios de Teoría Constitucional, Ed. Fontamara, México, 2007. pp. 29-30

Jellinek Georg, Trad. Posada Adolfo, La Declaración de los Derechos del Hombre y el Ciudadano, Ed. IIJ-UNAM, México, 2003.p.104

Ruipérez Alamillo, Javier, Reforma versus Revolución, Ed. Porrúa, México 2014.

Rubio Llorente, Francisco, La forma del poder, Constitucionales, Ed. Centro de Estudios, España 1997.

Pascua Mateo, El control de las elecciones, Ed. Thomson, España, 2009. 
SAMANIEGO SANTAMARIA, Luis Gerardo, "La Acción por Omisión Legislativa como medio de control constitucional en el Estado de Quintana Roo", en Derecho Constitucional Estatal Memorias del VI y VII Congresos Nacionales de Derechos Constitucionales de los Estados, Ed. UNAM. México, 2009. p. 411 y ss.

ZAGREBELSKY, Gustavo, el derecho dúctil: Ley, Derechos Justicia, $8^{\text {a }}$ edición, Ed. Trotta, Madrid, 2008. p. 14.

Principios y votos. El Tribunal Constitucional y la política, trad. de Manuel Martínez Neira, Ed. Trotta, Madrid 2008. 